\title{
Kinetic interpretation on mercury oxidation and transformation in simulated flue gases
}

\author{
H. Yang $\cdot$ W. Hou $\cdot$ H. Zhang $\cdot$ L. Zhou
}

Received: 8 October 2011/Revised: 18 December 2011/Accepted: 5 March 2012/Published online: 26 March 2013

(C) Islamic Azad University (IAU) 2013

\begin{abstract}
The approach coupled with computation fluid dynamics (CFD) and complex chemical kinetic computation to predict the oxidation of the elemental mercury in flue gas was discussed in this paper. According to the oxidation mechanism of the elemental mercury, the reactions which were in close relationship with mercury oxidation were determined by the sensitivity analysis method. The mercury oxidation process was simulated under the atmospheric pressure condition with different flue-gas compositions. The three-dimensional concentration distribution of mercury within the cylindrical flue duct and the impact of the temperature, concentration of $\mathrm{Cl}_{2}, \mathrm{HCl}, \mathrm{NO}$, and $\mathrm{O}_{2}$ on the mercury oxidation were also obtained. The simulation results were compared with the experimental results of Mamani-Paco and Widmer. The results show that coupling computation solves the problem of the combination of the CFD with the complex kinetic mechanism. The promotion effect of $\mathrm{Cl}_{2}$ on the oxidation of elemental mercury is much better than that of $\mathrm{HCl}$. The temperature window ranged from 950 to $1,150 \mathrm{~K}$ for the higher oxidizing rate of the elemental mercury was determined. The slight enhancement of $\mathrm{NO}$ on mercury oxidization was observed which was controlled by the competition between two reaction pathways. $\mathrm{O}_{2}$ weakly promotes homogeneous $\mathrm{Hg}$ oxidation, especially under the condition of high temperature. 1.1, 2.6 and $3.1 \%$ of mercury was oxidized in the presence of 0,4 and $16 \% \mathrm{O}_{2}$ at $600 \mathrm{~K}$, respectively. However, 12.5, 22.5 and $26.0 \%$ of $\mathrm{Hg}$ oxidation has been obtained at $1,200 \mathrm{~K}$.
\end{abstract}

H. Yang $(\bowtie) \cdot$ W. Hou $\cdot$ H. Zhang $\cdot$ L. Zhou

School of Energy and Mechanical Engineering,

Nanjing Normal University, Nanjing 210042,

Jiangsu, China

e-mail: yanghongmin@njnu.edu.cn
Keywords Mercury transformation - Chemical kinetics · Coupling $\cdot$ Computation fluid dynamics

\section{Introduction}

Trace element mercury in the coal may be emitted into atmosphere during the process of coal combustion, which will pollute the air and do harm for the health of humans. Coal-fired power plants have been considered to be the primary anthropogenic source of mercury into the atmosphere. In consequence, there have been initiatives to regulate the emission of mercury at a lower level and to develop the mercury emission control technologies. Mercury in the flue gas is most commonly classified in three forms: elemental mercury $\left(\mathrm{Hg}^{0}\right)$, gaseous oxidized mercury $\left(\mathrm{Hg}^{2+}\right)$ and particle-bound mercury $\left(\mathrm{Hg}_{\mathrm{p}}\right)$ (Luo et al. 2006; Chen et al. 2007; Lee et al. 2006a, b). The particulate bound mercury is usually trapped by ash collection devices within power plants, such as electrostatic precipitators (ESP), mechanical hoppers or bag houses. Oxidized forms of mercury (such as $\mathrm{HgCl}_{2}$ ) are easier to capture as they are water soluble and can be removed by wet scrubber technologies. $\mathrm{Hg}^{0}$ in the vapor phase is difficult to control and is likely to enter the global atmospheric cycle because of its high vapor pressure and low water solubility ( $\mathrm{Li}$ et al. 2003; Lee et al. 2006a, b; Duan et al. 2008). Hence, there are some trials to convert $\mathrm{Hg}^{0}$ into $\mathrm{Hg}^{2+}$ species such as $\mathrm{HgO}, \mathrm{HgSO}_{4}$ and $\mathrm{HgCl}_{2}$, in order to increase the removal efficiency of mercury.

In order to control mercury emissions effectively under a wide range of conditions, a predictive models need to be developed and supplied to process engineers to retrofit conventional APCDs or design new mercury abatement processes. A better understanding of mercury chemistry 
reaction mechanism of mercury conversion under different thermal and chemical conditions is needed to build such models. The chlorination of mercury is the most dominant mechanism during and after coal combustion. Several elemental research efforts have investigated the factors that affect homogeneous $\mathrm{Hg}$ speciation in flue gas or simulated flue gas. At flame temperatures, thermochemical equilibrium analysis indicates mercury will exist in the elemental state. As temperatures fall, the favored equilibrium product shifts to $\mathrm{HgCl}$. The crossover temperature between the elemental and oxidized forms increases from 530 to $740{ }^{\circ} \mathrm{C}$ as the background $\mathrm{HCl}$ concentration goes from 50 to 3,000 ppm. Hall et al. (1991, 1995) and Widmer and West (2000) proposed one-step global reaction mechanisms to model the observed depletion of $\mathrm{Hg}^{0}$ in the presence of $\mathrm{Cl}_{2}$ or $\mathrm{HCl}$. While such mechanisms can give plausible qualitative results, they are generally not suited for examining the effects of other flue gas constituents on $\mathrm{Hg}$ chlorination. Sliger and Kramlich (2000) published a model which was used to predict the data obtained in their experimental work. It was found that the model was able to predict about half of their experimental data accurately. However, several activation energy values used in key reactions were negative. Of those efforts, Edwards et al. (2001) provided the most complete $\mathrm{Hg}$ chlorination pathways to date as well as a pathway involving $\mathrm{HgO}$, with model predictions in good accord with experimental data for higher reactor temperatures but a drastic under-prediction of $\mathrm{Hg}$ chlorination for lower temperatures. Niksa et al. (2001) published a kinetic model to predict the importance of NO and $\mathrm{H}_{2} \mathrm{O}$ in a gas stream. The predictions seemed to correspond well with the experimental data. However, the authors made use of oxygen radicals for initiating the reaction between elemental $\mathrm{Hg}$ and $\mathrm{Cl}$ radicals, the results obtained were less realistic. Xu et al. (2003) published a detailed kinetic model consisting of 107 reactions and 30 species to simulate mercury speciation in flue gas. The performance of the model presented in their study was assessed through comparisons with the experimental results of Mamani-Paco and Helble (2000), Widmer and West (2000), and Sliger and Kramlich (2000). The results showed that the model calculations only followed the Sliger et al.'s experimental trends. Although great success has been achieved in understanding the kinetic mechanism during the conversion of the mercury speciation, the present modeling can only solve the transient or steady-state problems in a homogeneous stirred reactor. Typical computation fluid dynamics (CFD) solutions can only handle global (singlestep) reactions or a set of severely reduced chemical reaction steps while still producing a stable solution in a time-frame that suits modern design cycles. Low-emission combustion system design depends on the simulation of both chemical and fluid flows.
The coupling of CHEMKIN-CFD is a chemistry module that addresses the problem of CFD's computational stiffness by providing efficient and accurate solution algorithms that assure robust coupling of the chemistry and the flow. CHEMKIN-CFD needs a chemical-kinetics mechanism and thermodynamic data in CHEMKIN format, as well as optional CHEMKIN-based molecular-transport properties. CHEMKIN-CFD solves coupled conservation equations at every grid point, at every iteration and at every time-step within a CFD simulation.

This study focuses on developing an approach to simulate the conversion of mercury through both chemical and fluid flows aspects, which coupled with CFD and complex chemical kinetic computation. The goal of this research is to identify the major factors such as temperature, flue-gas constituents, which affect mercury speciation and conversion in flue gas. The understanding of mercury oxidization may help predict conversion of mercury speciation in flue gases from coal-fired utility boilers, which will be helpful toward the research of mercury control technology. The work was carried out in Nanjing Normal University during 2010.9-2011.5.

\section{Materials and methods}

The simplified assumptions made for the oxidation process of gaseous mercury in this model are as follows:

1) Mercury reaction is simplified as homogenous reaction of $\mathrm{Hg}$ and $\mathrm{Cl}$;

2) Since the shape of flue has certain symmetry, the gas flow in the flue is simplified as one-dimensional plug flow model;

3) Only $\mathrm{C}, \mathrm{H}, \mathrm{O}, \mathrm{N}, \mathrm{Hg}$ and $\mathrm{Cl}$ are considered in the model.

\section{Physical model}

In simulation, similar to the Mamani-Paco and Helble (2000) experiment, a three-dimensional cylinder with a radius of 2.5 and $10.5 \mathrm{~m}$ in height was considered. The first step of the CFD simulation was the mesh generation. The quality of grid generation has great significance on computational simulation. Since the shape of flue has certain symmetry, the flue was assumed as a straight pipe. A simple three-dimensional axial symmetry model was created and meshed using Gambit software, as is shown in Fig. 1.

Mathematic model

Numerical 3D predictions have been carried out with the finite volume code Fluent 6.2.16 using an standard $k-\varepsilon$ 
Fig. 1 Grid schematic a Plane grid at $z=10 \mathrm{~m}$. b Plane grid at $x=0 \mathrm{~m}$

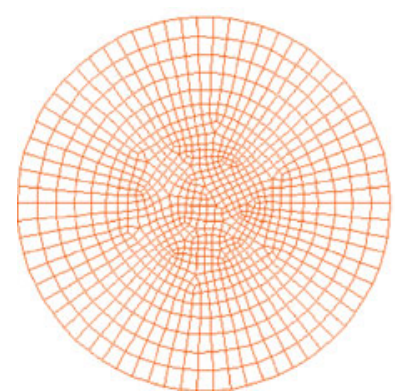

(a)

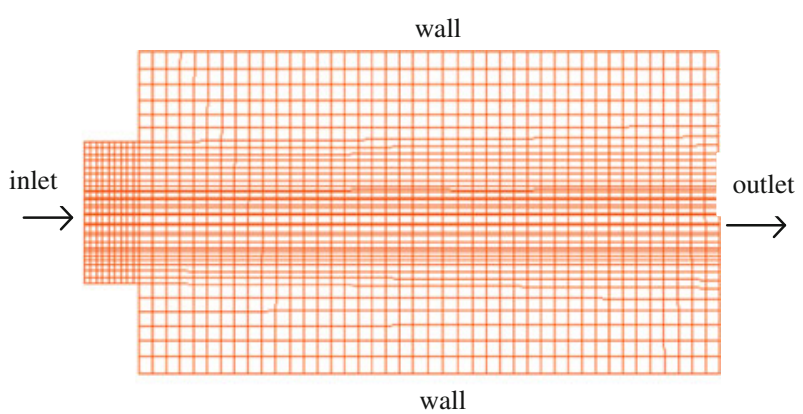

(b) model for turbulence which is the most widely used and validated turbulence model (Patankar 1980). The value of each coefficient in this model is: $c_{\mu}=0.09, c_{1}=1.44$, $c_{2}=1.92, \sigma_{k}=1.0$ and $\sigma_{\varepsilon}=1.3$. For steady, incompressible flow, momentum equations, energy and species conservation equations are taking into account.

In order to reflect the influence of chemical reaction and turbulence in the flue gas on mercury oxidation, based on Eddy Dissipation Concept (EDC) model, 3-D double precision solver is selected for computation (Magnussen 1981; Gran and Magnussen 1996). CHEMKIN-CFD can be more efficient than CFD chemistry solvers in converging to a solution. In this paper, FLUENT is used to calculate the flow field, which was coupled with the CHEMKIN kinetic mechanism to obtain the concentration distribution mercury and other compositions in the flue gas.

\section{Chemical reaction model}

The reduced chemical reaction mechanism consisting of 22 species and 26 reactions proposed by Widmer and Sliger et al. is adopted, which is widely verified by experiments and applied in coal-fired gas purification simulation. Main reaction mechanism in this model includes eight reactions between mercury and chlorine, which describe the oxidation mechanism of mercury and the 18 elementary reactions involving chlorine are taken from Sliger, which are obtained from NIST database.

\section{Boundary conditions}

Velocity-inlet boundary condition is defined at the inlets. Velocity at the inlet is $7.5-15 \mathrm{~m} / \mathrm{s}$ according to the resident time. The pressure at the outlet is defined as normal atmosphere and the exterior walls were modeled as adiabatic. The "no-slip" boundary condition was used for the gas phase at the wall, with only the tangential velocity and then keeping the constant temperature at $400 \mathrm{~K}$.

\section{Results and discussion}

The $\mathrm{Hg}^{0}$ conversion rate is defined as:

$\mathrm{Hg}^{0}$ conversion rate $=\frac{\left[\mathrm{Hg}^{0}\right]_{\text {in }}-\left[\mathrm{Hg}^{0}\right]_{\text {out }}}{\left[\mathrm{Hg}^{0}\right]_{\text {in }}}$

where $\left[\mathrm{Hg}^{0}\right]_{\text {out }}$ and $\left[\mathrm{Hg}^{0}\right]_{\text {in }}$ are the concentrations of $\mathrm{Hg}^{0}$ measured at the outlet and inlet of the reactor, respectively.

Sensitivity analysis of oxidation reaction on $\mathrm{Hg}^{0}$

Sensitivity analysis is a formal procedure to determine quantitatively how the solution to a model depends on certain parameters in the model formulation. The sensitivity analysis allows to understand how the model will respond to changes in the rate parameters. It also provides insight about how important certain reaction pathways are to the model's predictions.

Table 1 shows the oxidation pathway of $\mathrm{Hg}^{0}$. The rate coefficients are in the modified Arrhenius form, $k=A T^{\beta}$ $\exp (-E / R T)$. Elemental mercury was chosen as reference species, and sensitivity analysis was carried out for the eight oxidation reactions at $1,195 \mathrm{~K}$, in the presence of $50 \mathrm{ppm} \mathrm{HCl}$. The composition of flue gas is the same as the experiment made by Sliger and Kramlich (2000), as is shown in Table 2. The greater the absolute value of the sensitivity coefficient $(\mathrm{S})$ is, the more effect of this reaction on $\mathrm{Hg}^{0}$ will be. The results were shown in Fig. 2 .

Sensitivity analysis indicates that mercury oxidation was most sensitive to the coefficients of reactions R1, R7 and R5 listed in Table 1, which is consistent with the simulation result of $\mathrm{Xu}$ et al. (2003). When time is approaching $1.4 \mathrm{~s}$, the absolute values of these reactions' sensitivity coefficient all exceed 3.0E-7. The sensitivity coefficients of other reactions are relatively lower. The sensitivity analyses show that mercury is oxidized by a $\mathrm{Cl}$-atom recycle process, so that the concentrations of both $\mathrm{Cl}$ and $\mathrm{HOCl}, \mathrm{HCl}$ are the important components containing 
Table1 The reactions rate coefficient data using the modified Arrhenius form $k=A T^{\beta} \exp (-E / R T)$ involved in mercury oxidation mechanism

\begin{tabular}{|c|c|c|c|c|c|}
\hline NO. & Reactions & $E /\left(\mathrm{cal} \cdot \mathrm{mol}^{-1}\right)$ & $\beta$ & $A /\left(\mathrm{cm}^{3} / \mathrm{mol}-\mathrm{sec}\right)$ & Source \\
\hline $\mathrm{R} 1$ & $\mathrm{Hg}+\mathrm{Cl}+\mathrm{M}=\mathrm{HgCl}+\mathrm{M}$ & $-14,400$ & 1.4 & $2.40 \mathrm{E} 8$ & Widmer \\
\hline $\mathrm{R} 2$ & $\mathrm{Hg}+\mathrm{Cl}_{2}=\mathrm{HgCl}+\mathrm{Cl}$ & 34,000 & 0.0 & $1.39 \mathrm{E} 14$ & Widmer \\
\hline $\mathrm{R} 3$ & $\mathrm{HgCl}+\mathrm{Cl}_{2}=\mathrm{HgCl}_{2}+\mathrm{Cl}$ & 1,000 & 0.0 & $1.39 \mathrm{E} 14$ & Widmer \\
\hline $\mathrm{R} 4$ & $\mathrm{HgCl}+\mathrm{Cl}+\mathrm{M}=\mathrm{HgCl}_{2}+\mathrm{M}$ & 3,100 & 0.0 & $2.19 \mathrm{E} 18$ & Widmer \\
\hline $\mathrm{R} 5$ & $\mathrm{Hg}+\mathrm{HOCl}=\mathrm{HgCl}+\mathrm{OH}$ & 19,000 & 0.0 & $4.27 \mathrm{E} 13$ & Widmer \\
\hline R6 & $\mathrm{Hg}+\mathrm{HCl}=\mathrm{HgCl}+\mathrm{H}$ & 79,300 & 0.0 & $4.94 \mathrm{E} 14$ & Widmer \\
\hline R7 & $\mathrm{HgCl}+\mathrm{HCl}=\mathrm{HgCl}_{2}+\mathrm{H}$ & 21,500 & 0.0 & $4.94 \mathrm{E} 14$ & Widmer \\
\hline $\mathrm{R} 8$ & $\mathrm{HgCl}+\mathrm{HOCl}=\mathrm{HgCl}_{2}+\mathrm{OH}$ & 1,000 & 0.0 & 4.27E13 & Widmer \\
\hline R9 & $\mathrm{Cl}+\mathrm{Cl}+\mathrm{M}=\mathrm{Cl} 2+\mathrm{M}$ & $-1,800$ & 0.0 & 14.400 & Sliger \\
\hline $\mathrm{R} 10$ & $\mathrm{H}+\mathrm{Cl}+\mathrm{M}=\mathrm{HCl}+\mathrm{M}$ & 0 & 0.0 & 17.000 & Sliger \\
\hline R11 & $\mathrm{HCl}+\mathrm{H}=\mathrm{H}_{2}+\mathrm{Cl}$ & 3,500 & 0.0 & 13.360 & Sliger \\
\hline $\mathrm{R} 12$ & $\mathrm{H}+\mathrm{Cl}_{2}=\mathrm{HCl}+\mathrm{Cl}$ & 1,200 & 0.0 & 13.930 & Sliger \\
\hline $\mathrm{R} 13$ & $\mathrm{O}+\mathrm{HCl}=\mathrm{OH}+\mathrm{Cl}$ & 3,510 & 2.87 & 3.530 & Sliger \\
\hline $\mathrm{R} 14$ & $\mathrm{OH}+\mathrm{HCl}=\mathrm{Cl}+\mathrm{H}_{2} \mathrm{O}$ & -223 & 1.65 & 7.430 & Sliger \\
\hline R15 & $\mathrm{O}+\mathrm{Cl}_{2}=\mathrm{ClO}+\mathrm{Cl}$ & 3585 & 0.0 & 12.790 & Sliger \\
\hline R16 & $\mathrm{O}+\mathrm{ClO}=\mathrm{Cl}+\mathrm{O}_{2}$ & -193 & 0.0 & 13.200 & Sliger \\
\hline $\mathrm{R} 17$ & $\mathrm{Cl}+\mathrm{HO}_{2}=\mathrm{HCl}+\mathrm{O}_{2}$ & 894 & 0.0 & 13.030 & Sliger \\
\hline $\mathrm{R} 18$ & $\mathrm{Cl}+\mathrm{HO}_{2}=\mathrm{OH}+\mathrm{ClO}$ & -338 & 0.0 & 13.390 & Sliger \\
\hline $\mathrm{R} 19$ & $\mathrm{Cl}+\mathrm{H}_{2} \mathrm{O}_{2}=\mathrm{HCl}+\mathrm{HO}_{2}$ & 1951 & 0.0 & 12.800 & Sliger \\
\hline $\mathrm{R} 20$ & $\mathrm{ClO}+\mathrm{H}_{2}=\mathrm{HOCl}+\mathrm{H}$ & 14,100 & 0.0 & 11.780 & Sliger \\
\hline $\mathrm{R} 21$ & $\mathrm{H}+\mathrm{HOCl}=\mathrm{HCl}+\mathrm{OH}$ & 7,620 & 0.0 & 13.980 & Sliger \\
\hline $\mathrm{R} 22$ & $\mathrm{Cl}+\mathrm{HOCl}=\mathrm{HCl}+\mathrm{ClO}$ & 258 & 0.0 & 12.260 & Sliger \\
\hline $\mathrm{R} 23$ & $\mathrm{Cl}_{2}+\mathrm{OH}=\mathrm{Cl}+\mathrm{HOCl}$ & 1,810 & 0.0 & 12.100 & Sliger \\
\hline $\mathrm{R} 24$ & $\mathrm{O}+\mathrm{HOCl}=\mathrm{OH}+\mathrm{ClO}$ & 4,372 & 0.0 & 12.780 & Sliger \\
\hline $\mathrm{R} 25$ & $\mathrm{OH}+\mathrm{HOCl}=\mathrm{H}_{2} \mathrm{O}+\mathrm{ClO}$ & 994 & 0.0 & 12.255 & Sliger \\
\hline $\mathrm{R} 26$ & $\mathrm{HOCl}+\mathrm{M}=\mathrm{OH}+\mathrm{Cl}+\mathrm{M}$ & 56,720 & -3.0 & 10.250 & Sliger \\
\hline
\end{tabular}

Table 2 Flue gas compositions for the experiments

\begin{tabular}{llll}
\hline Species & \multicolumn{2}{l}{ Composition (mole fraction) } & \\
\cline { 2 - 4 } & Mamani-Paco and Helble (2000) & Widmer and West (2000) & Sliger and Kramlich (2000) \\
\hline $\mathrm{O}_{2}$ & 0.0 & 0.10 & 0.0743 \\
$\mathrm{CO}_{2}$ & 0.13 & 0.10 & 0.0615 \\
$\mathrm{H}_{2} \mathrm{O}$ & 0.26 & 0.08 & 0.123 \\
$\mathrm{Hg}^{0}$ & $50 \mu \mathrm{g} / \mathrm{m}^{3}$ & $370 \mathrm{E}-9$ & $53 \mu \mathrm{g} / \mathrm{m}^{3}$ \\
$\mathrm{Cl}_{2}$ & Varied as indicated & Not defined & Not defined \\
$\mathrm{HCl}$ & Not defined & $3,000 \mathrm{E}-6$ & Varied as indicated \\
$\mathrm{N}_{2}$ & Balance & Balance & Balance \\
\hline
\end{tabular}

chlorine in the reaction system, which has significant effect on mercury oxidation.

\section{Effects of $\mathrm{Cl}_{2}$ on mercury oxidation}

The effects of $\mathrm{Cl}_{2}$ concentration on $\mathrm{Hg}$ conversion were studied in detail by experiments of Mamani-Paco and Helble (2000). For all cases, the residence time is approximately $1.4 \mathrm{~s}$. The reaction temperature and pressure are $1,353 \mathrm{~K}$ and $1 \mathrm{~atm}$, respectively. The chlorine concentrations in the flue gas ranged between 50, 100, and $300 \mathrm{ppm}$. Initial compositions of the flue gas are shown in Table 2. In order to verify the precision of modeling prediction in this paper, the kinetic simulation results were compared with the experimental data of Mamani-Paco. The results are illustrated in Fig. 3. In Mamani-Paco et al. experiment, with the increasing of $\mathrm{Cl}_{2}$ from 50, 100 and 300 ppm, 8.5, 38.5 and $65.5 \%$ of the mercury was oxidized in average. In kinetic calculations, $17.5,32.5$ and $55.4 \%$ of the mercury was oxidized in the presence of 50, 100 and $300 \mathrm{ppm}$ 


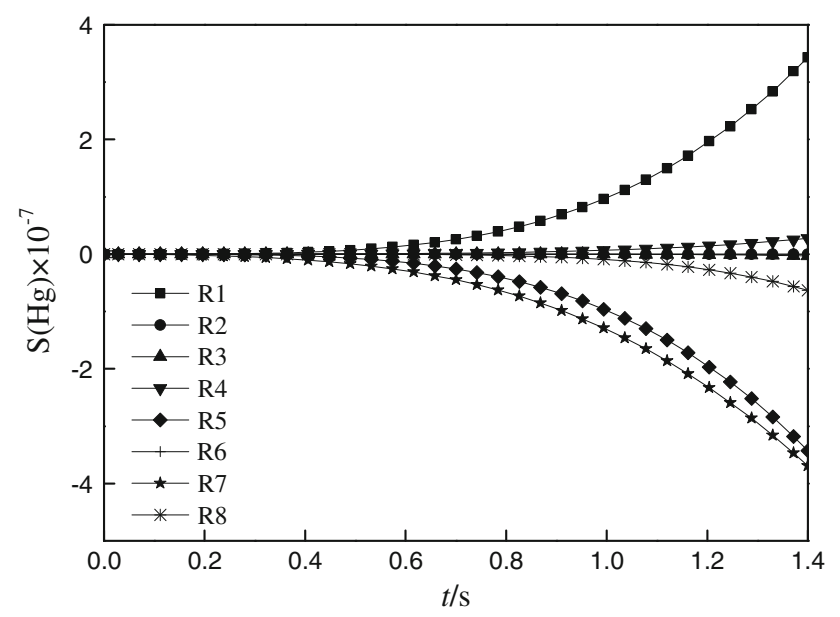

Fig. $2 \mathrm{Hg}$ sensitivity derivatives versus time for present mechanism

$\mathrm{Cl}_{2}$, respectively. It shows that the prediction results in this paper are consistence with Mamani-Paco and Helble (2000) experimental data and $\mathrm{Xu}$ et al. (2003) calculation results.

The distributions of elemental mercury concentration in reactor are shown in Fig. 4. It is obviously that $\mathrm{Hg}^{\mathrm{O}}$ is oxidized quickly after entering the reactor. The concentration of elemental mercury is decreased along the central axes and mercury is also oxidized when spreading toward the pipe wall. When $\mathrm{Cl}_{2}$ concentration increased from 50 to $300 \mathrm{ppm}$, the oxidation of mercury is enhanced to a great extent. The increasing of $\mathrm{Cl}_{2}$ concentration promoted the oxidation of elemental mercury. The oxidation process took place in the whole reactor. As mentioned in MamaniPaco et al.'s experimental work, the mercury concentration was only monitored at exit of the reactor to obtain the oxidation efficiency of elemental mercury through reactor. The previous modeling works also gave the results in a

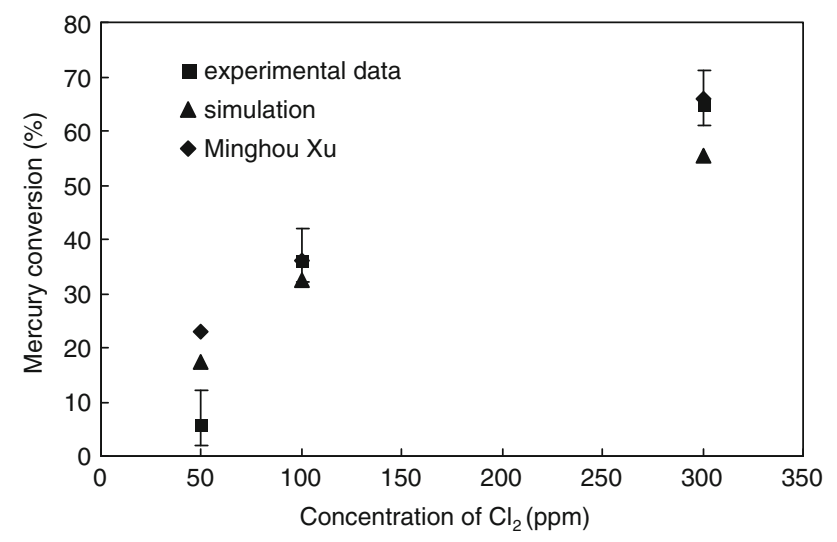

Fig. 3 Comparison of the kinetic model predictions with MamaniPaco and Helble (2000) experimental data and Xu et al. (2003) model predictions closed, steady-state perfectly stirred reactor. The results in this work presented the transient 3D concentration distribution in a practical reactor which coupled with fluid dynamic in detail. The oxidation efficiency at exit of reactor agreed with the experimental results of MamaniPaco et al.'s work.

\section{Effects of $\mathrm{HCl}$ on mercury oxidation}

In order to investigate the effect of both $\mathrm{HCl}$ and $\mathrm{Cl}_{2}$ on the oxidation of mercury in gas, an experiment was also conducted with both $\mathrm{HCl}$ and $\mathrm{Cl}_{2}$ present simultaneously by Mamani-Paco and Helble (2000). This experiment was conducted in the presence of $50 \mu \mathrm{g} / \mathrm{m}^{3}$ mercury, $50 \mathrm{ppm}$ $\mathrm{Cl}_{2}$ and $100 \mathrm{ppm} \mathrm{HCl}$. It is observed that when the total concentration of $\mathrm{Cl}$ increased, the mercury oxidation rate has only a little difference with that when only $50 \mathrm{ppm} \mathrm{Cl}_{2}$ exists. Kinetic modeling was also carried out in this paper to simulate this phenomenon. The simulation results under both conditions are shown in Fig. 5. In the presence of $50 \mathrm{ppm} \mathrm{Cl}_{2}$ with and without $\mathrm{HCl}(100 \mathrm{ppm})$, the mercury concentration decreases along the axial distance in the reactor. Although both $\mathrm{Cl}_{2}$ and $\mathrm{HCl}$ introduced atom $\mathrm{Cl}$ in reaction zone, similar mercury oxidation efficiency (about $18.2 \%$ ) was observed at the exit of reactor, which is consistent with the results obtained for oxidation with $\mathrm{Cl}_{2}$ alone. These results are in accord with Mamani-Paco and Helble (2000) experimental data.

Prediction of mercury conversion at different temperature

The effects of temperature on $\mathrm{Hg}$ concentration were studied, in which the gas compositions was the same as that in Widmer et al. experiment. The pressure is 1 atm. Residence times for each temperature are listed in Table 3.

Figure 6 shows the comparison of predicted $\mathrm{Hg}$ conversion with the experimental and modeling data of Widmer and West (2000), Edwards et al. (2001) and Xu et al. (2003)'s model predictions. Widmer and West (2000) kinetic mechanism agreed with the experimental conversion of mercury, but the deviation at high temperature is great where mercury conversion is thermodynamically controlled. There are deviations among other three calculation results, especially at lower temperatures, but they can follow the similar mercury conversion trend. The temperature window for the higher oxidation rate of the elemental mercury is in the range from 950 to $1,150 \mathrm{~K}$ range. When the temperature is above $1,100 \mathrm{k}$, the mercury oxidation rate will decreased. However, the result trends of the four groups are generally the same. The reason for this discrepancy may result from the difference of parameters in oxidation mechanism and kinetics. 
Fig. 4 The mole concentration distribution of elemental mercury for different concentration of $\mathrm{Cl}_{2}$ in flue gas
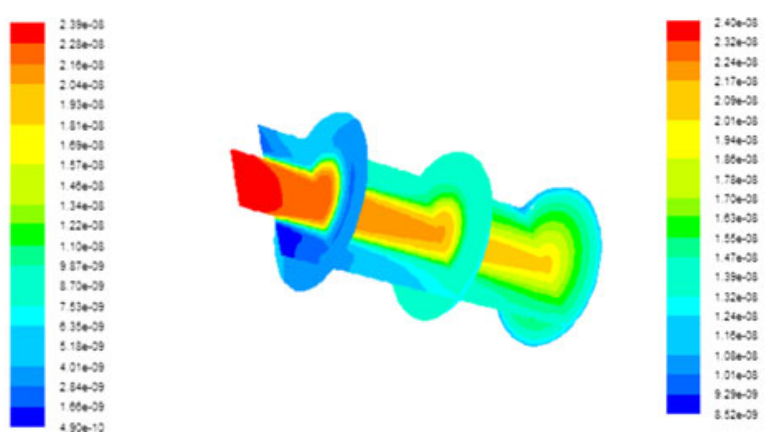

(a) $300 \mathrm{ppm} \mathrm{Cl}$
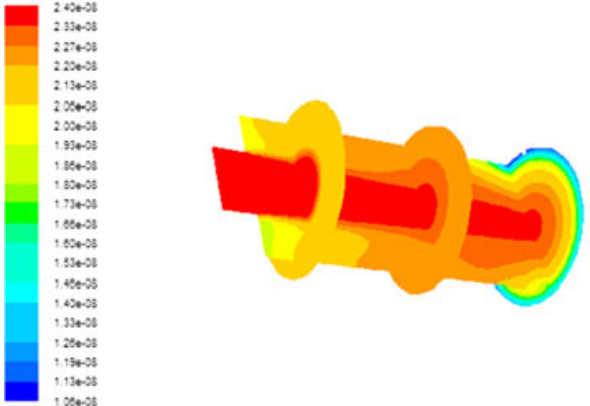

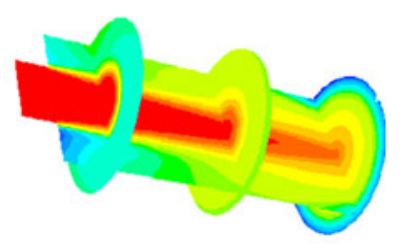

(b) $100 \mathrm{ppm} \mathrm{Cl} 2$

(c) $50 \mathrm{ppm} \mathrm{Cl} 2$

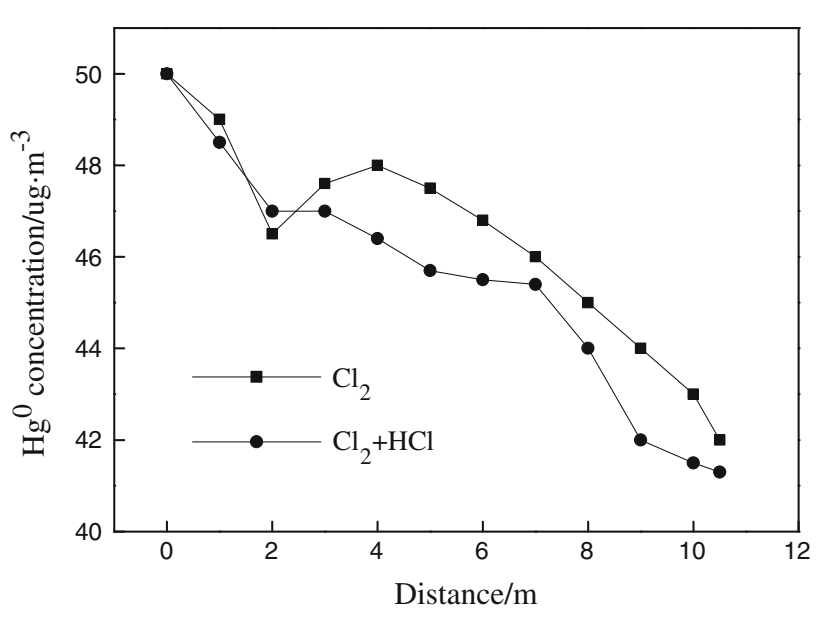

Fig. 5 The effect of $\mathrm{Cl}_{2}$ and $\mathrm{HCl}$ on mercury concentration in reactor (Kinetic calculations)

Table 3 Experimental conditions for Widmer et al. experiment

\begin{tabular}{lll}
\hline Gas temperature $(\mathrm{K})$ & $\begin{array}{l}\mathrm{HCl} \\
\text { concentration } \\
(\mathrm{ppm})\end{array}$ & $\begin{array}{l}\text { Residence } \\
\text { time }(\mathrm{sec})\end{array}$ \\
\hline 696 & 3,000 & 1.16 \\
790 & 3,000 & 1.02 \\
904 & 3,000 & 0.89 \\
1,044 & 3,000 & 0.77 \\
1,149 & 3,000 & 0.70 \\
\hline
\end{tabular}

Effects of NO on mercury oxidation

Nitric oxide is a common constituent in real flue gas. The complex impact of $\mathrm{NO}$ on homogeneous mercury oxidation has a potentially important practical implication. The simulation was carried out under the gas composition condition as $\mathrm{CO}_{2}(13 \%), \mathrm{O}_{2}(4 \%), \mathrm{HCl}(60 \mathrm{ppm}), \mathrm{Hg}^{0}$ $\left(18.75 \mu \mathrm{g} \cdot \mathrm{m}^{-3}\right)$, NO $(0,400$ and $800 \mathrm{ppm})$ and $\mathrm{N}_{2}$ as balance. The chemical reaction mechanism consisting of 30 species and 107 reactions proposed by $\mathrm{Xu}$ et al. (2003)

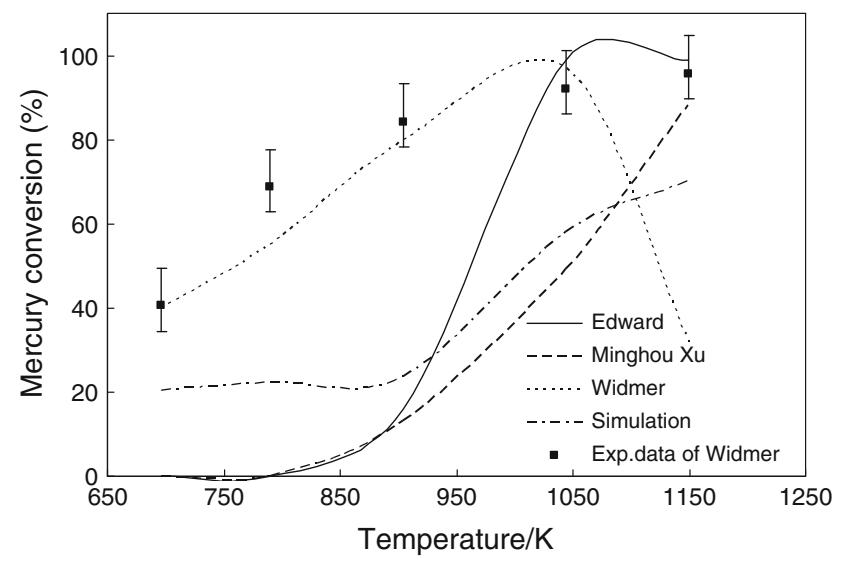

Fig. 6 Comparison of the kinetic model predictions with the with the experimental and modeling data of Widmer and West (2000), Edwards et al.'s (2001) and Xu et al. (2003)'s model predictions in the presence of $3,000 \mathrm{ppm} \mathrm{HCl}$ 
was applied. As shown in the Fig. 7, NO enhances mercury oxidization slightly in the $\mathrm{CO}_{2} / \mathrm{O}_{2} / \mathrm{N}_{2} / \mathrm{HCl} / \mathrm{Hg}$ system at low temperature zone. The maximum oxidation rate was obtained for $400 \mathrm{ppm}$ of NO at 1,200 K. The oxidation rate dropped to $7.8 \%$ for $800 \mathrm{ppm} \mathrm{NO}$ at same condition. Zhou et al. (2007) presented the following possible reaction pathway when $\mathrm{NO}$ was added to $\mathrm{CO}_{2} / \mathrm{O}_{2} / \mathrm{N}_{2} / \mathrm{HCl} / \mathrm{Hg}$ system which supported the oxidation promotion process at low temperature is as follows:

$\mathrm{NO}(\mathrm{g})+\mathrm{O}_{2}(\mathrm{~g})=\mathrm{NO}_{2}+\mathrm{O}$

Elemental mercury is hypothesized to react with active $\mathrm{O}$ atoms and produced $\mathrm{HgO}(\mathrm{s}, \mathrm{g})$ via the following pathways.

$\mathrm{Hg}(\mathrm{g})+\mathrm{O}=\mathrm{HgO}(\mathrm{s}, \mathrm{g})$

$\mathrm{Hg}(\mathrm{g})+\mathrm{NO}_{2}(\mathrm{~g})=\mathrm{HgO}(\mathrm{s}, \mathrm{g})+\mathrm{NO}(\mathrm{g})$

Furthermore, active $\mathrm{O}$ atoms reacted with $\mathrm{HCl}$ to form $\mathrm{HOCl}(\mathrm{g})$ via

$\mathrm{HCl}(\mathrm{g})+\mathrm{O}(\mathrm{g})=\mathrm{HOCl}(\mathrm{g})$

and then $\mathrm{HOCl}$ oxidized $\mathrm{Hg}^{0}$ vapor to $\mathrm{HgCl}_{2}$ via the following pathways:

$\mathrm{Hg}(\mathrm{g})+\mathrm{HOCl}(\mathrm{g})=\operatorname{HgCl}(\mathrm{s}, \mathrm{g})+\mathrm{OH}(\mathrm{g})$

$\mathrm{HgCl}(\mathrm{s}, \mathrm{g})+\mathrm{HOCl}(\mathrm{g})=\mathrm{HgCl}_{2}(\mathrm{~s}, \mathrm{~g})+\mathrm{OH}(\mathrm{g})$

It has been reported that $\mathrm{NO}$ can either promote or inhibit mercury oxidation, depending upon the NO concentration (Niksa et al. 2001a, b).The previous work noted that NO can potentially be an effective inhibitor of mercury oxidation through its effect in reducing the concentration of $\mathrm{OH}$ in the flue gas. The formation of $\mathrm{HOCl}$ from $\mathrm{OH}$ and $\mathrm{Cl}$ is essential for the oxidization of $\mathrm{Hg}$, which oxidizes $\mathrm{HgCl}$ into $\mathrm{HgCl}_{2}$ and $\mathrm{OH}$. The elimination of $\mathrm{OH}$ resulted in following reaction (8):

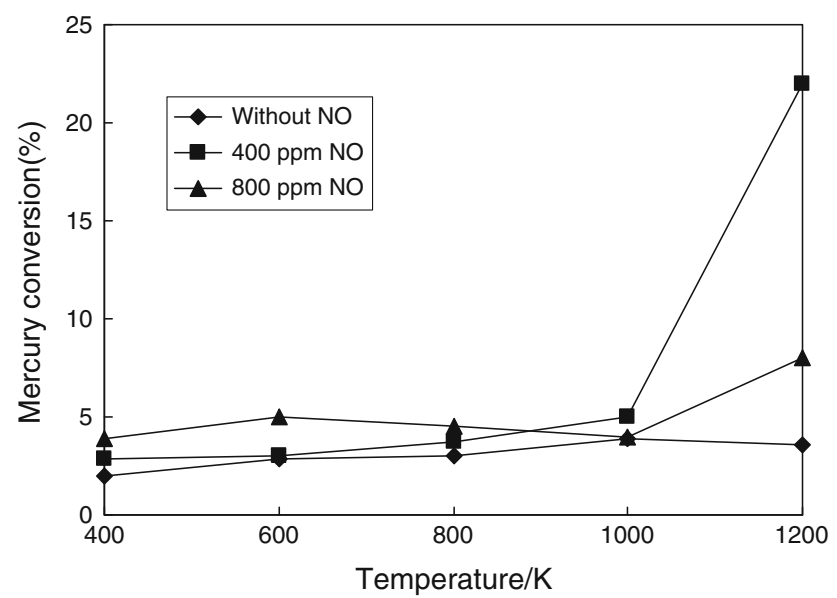

Fig. 7 Effect of $\mathrm{NO}$ on $\mathrm{Hg}$ transformation
$\mathrm{OH}(\mathrm{g})+\mathrm{NO}(\mathrm{g})+\mathrm{M}=\mathrm{HONO}(\mathrm{g})+\mathrm{M}$

which was believed to inhibit mercury oxidization (Zhou et al. 2007). Therefore, the conversion of $\mathrm{NO}$ in the $\mathrm{CO}_{2}-$ $\mathrm{O}_{2}-\mathrm{N}_{2}-\mathrm{HCl}$ system was dependent on the competition between reactions (2)-(7) and (8).

Effects of $\mathrm{O}_{2}$ on mercury oxidation

On the basis of 3.4, the extent of mercury conversion under different $\mathrm{O}_{2}$ concentrations, 0,4 and $16 \%$, was obtained. For all cases, the residence time is approximately $2.0 \mathrm{~s}$. It can be seen that $\mathrm{O}_{2}$ weakly promotes homogeneous $\mathrm{Hg}$ oxidation, especially under the condition of high temperature, as illustrated in Fig. 8.

As indicated in sensitivity analysis above, the key pathway of mercury oxidation is reaction associated with $\mathrm{Cl}$ and $\mathrm{Cl}_{2}$ species. In simulated flue gas, $\mathrm{Cl}$ and $\mathrm{Cl}_{2}$ come from the following reactions:

$\mathrm{HCl}(\mathrm{g})+\mathrm{OH}(\mathrm{g})=\mathrm{H}_{2} \mathrm{O}(\mathrm{g}, \mathrm{l})+\mathrm{Cl}(\mathrm{g})$

$\mathrm{Cl}(\mathrm{g})+\mathrm{Cl}(\mathrm{g})+\mathrm{M}=\mathrm{Cl}_{2}(\mathrm{~g})+\mathrm{M}$

The presence of oxygen will promote the generation of the $\mathrm{OH}$ through reactions (11) and (12) at high temperature:

$\mathrm{H}(\mathrm{g})+\mathrm{O}_{2}(\mathrm{~g})=\mathrm{O}(\mathrm{g})+\mathrm{OH}(\mathrm{g})$

$\mathrm{H}(\mathrm{g})+\mathrm{O}(\mathrm{g})+\mathrm{M}=\mathrm{OH}(\mathrm{g})+\mathrm{M}$

Other literatures indicated that the reactions (13) and (14) also play important roles to oxidize elemental mercury.

$\mathrm{Hg}(\mathrm{g})+\mathrm{O}_{2}(\mathrm{~g})=\mathrm{HgO}(\mathrm{s}, \mathrm{g})$

$\mathrm{Hg}(\mathrm{g})+\mathrm{OH}=\mathrm{HgOH}$

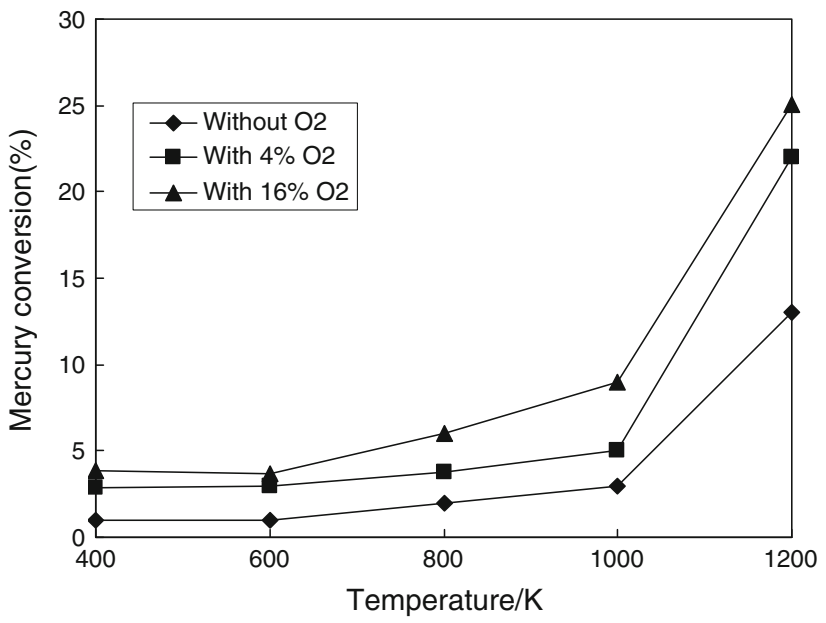

Fig. 8 Effect of $\mathrm{O}_{2}$ fraction on $\mathrm{Hg}$ transformation 


\section{Conclusion}

A method to simulate the oxidation and conversion of the elemental mercury in flue gas which coupled with CFD and complex chemical kinetic computation was presented in this paper. The three-dimensional concentration distribution of mercury within the cylindrical reactor was obtained. The impact of the temperature and compositions of flue gas were also discussed and the simulation results were compared with the experimental results of Mamani-Paco and Widmer. More mercury oxidization occurs with a higher reaction temperature and higher $\mathrm{Cl}_{2}$ concentration in the flue gases. In the present work, NO enhances mercury oxidization process which was dependent on the competition between reactions (2)-(7) and (8). $\mathrm{O}_{2}$ weakly promotes homogeneous mercury oxidation, especially under the condition of high temperature. The possible pathway of this enhancement related to the direct oxidation of $\mathrm{O}$ atom, $\mathrm{OH}$ radical and attendant $\mathrm{Cl}$ atom which was induced by the presence of oxygen.

Acknowledgments Grateful acknowledgments for the financial support from National Natural Science Foundation of China (50976049) and Natural Science Foundation of Jiangsu Province (BK2011788).

\section{References}

Chen L, Duan YF, Zhuo YQ (2007) Mercury transformation across particulate control devices in six power plants of China: the coeffect of chlorine and ash composition[J]. Fuel 86:603-610

Duan YF, Jiang YM, Yang LG (2008) Experimental study on mercury emission and adsorption in circulating fluidized bed boiler[J]. Proceedings of the Chinese Society of Electrical Engineering 28, $1-5$

Edwards JR, Srivastava RK, Kilgroe JD (2001) A study of gas 2 phase mercury speciation using detailed chemical kinetics[J]. J Air Waste Manag Assoc 51:869-877

Gran IR, Magnussen BF (1996) A numerical study of a bluff-body stabilized diffusion flame[J]. Combust Sci Technol 119:119-191

Hall B, Schager P, Ljungstrom E (1991) Chemical reactions of mercury in combustion flue gases[J]. Water Air Soil Pollut $56: 3-14$
Hall B, Schager P, Weesmaa J (1995) The homogeneous gas phase reaction of mercury with oxygen, and the corresponding heterogeneous reactions in the presence of activated carbon and fly ash[J]. Chemosphere 30:611-627

Lee SJ, Seo YC, Jang HN, Park KS, Baek JI, An HS, Song KC (2006a) Speciation and mass distribution of mercury in a bituminous coalfired power plant[J]. Atmos Environ 40:22152224

Lee JY, Ju Y, Keener TC, Rajender SV (2006b) Development of costeffective noncarbon sorbents for $\mathrm{Hg}^{0}$ removal from coal-fired power plants [J]. Environ Sci Technol 40:2714-2720

Li LC, Ping P, Tian AM, Xu MH, Zheng CG, Wong NB (2003) A study on there action mechanism and kinetic of mercury oxidation bychlorine species[J]. J Mol Struct (Theochem) 625:277-281

Luo ZY, Hu CX, Zhou JS, Cen KF (2006) Stability of mercury on three activated carbon sorbents[J]. Fuel Process Technol 87: $679-685$

Magnussen BF (1981) On the structure of turbulence and a generalized dddy dissipation Concept for Chemical Reaction in Turbulent Flow[C]. Nineteenth AIAA Meeting, St. Louis

Mamani-Paco RM, Helble JJ (2000) Bench-scale examination of mercury oxidation under non-isothermal conditions[R]. The 93rd Annua Meeting, Air\&Waste Management Association, Salt Lake City, Utah

Niksa S, Helble JJ, Fujiwara N (2001a) Kinetic modeling of homogeneous mercury oxidation: the importance of $\mathrm{NO}$ and $\mathrm{H}_{2} \mathrm{O}$ inpredicting oxidation in coal-derived systems[J]. Environ Sci Technol 35:3701-3706

Niksa S, Helble JJ, Fujiwara N (2001b) Interpreting laboratory test data on homogeneous mercury oxidation in coal-derived exhausts[C]. The 94th Annual Meeting of the Air and Waste Management Association, Orlando, FL, June 24-28

Patankar SV (1980) Numerical heat transfer and fluid flow. Hemisphere, Washington

Sliger RN, Kramlich JC (2000) Towards the development of a chemical kinetic model of the homogeneous oxidation of mercury by chlorine species[J]. Fuel Process Technol 65-66:423-438

Widmer NC, West J (2000) Thermochemical study of mercury oxidation in utility boiler fuel gases[C].The 93rd Annual Meeting, Air\&Waste Management Association, Salt Lake City, Utah

Xu MH, Qiao Y, Zheng CG, Li LC, Jing Liu (2003) Modeling of homogeneous mercury speciation using detailed chemical kinetics [J]. Combust Flame 132:208-218

Zhou JS, Luo ZY, Hu CX, Cen KF (2007) Factors impacting gaseous mercury speciation in postcombustion[J]. Energy Fuels 21: $491-495$ 